\title{
Cooperação Internacional para o Desenvolvimento: o Caso Brasileiro
}

\author{
International Cooperation and Development: The Brazilian Case
}

\section{Patrícia Andrade de Oliveira e Silva ${ }^{a}$ Niemeyer Almeida Filho ${ }^{\text {b }}$}

\begin{abstract}
Resumo: a Cooperação Internacional para o Desenvolvimento (CID) emergiu após a Segunda Guerra Mundial em busca de soluções para questões internacionais relacionadas ao desenvolvimento. No Brasil, após os anos 2000, o destaque da política social despertou o interesse dos gestores internacionais e a parceria entre a ONU e o país na implementação de estratégias similares em outros países cresceu exponencialmente, evidênciando a Cooperação Sul-Sul (CSS), onde as experiências de sucesso em determinado país do Sul servem como exemplo para os demais. Entretanto, a crise política e econômica atual trará efeitos para a cooperação internacional e, por isso, pretende-se investigar a motivação, o papel da CSS brasileira na última década e quais serão os prováveis efeitos da atual crise, através da revisão bibliográfica e dos dados disponíveis.
\end{abstract}

Palavras-chave: Cooperação Internacional; Cooperação Sul-Sul; Políticas Públicas. Classificação JEL: O19

\begin{abstract}
International Cooperation and Development (ICD) emerged after the Second World War searching for solutions to international issues related to development. In Brazil, especially after 200o's, the highlight of social policy is evident, rising the interest of international agents. The partnership between the UN and Brazilian government on implementation of similar public policies in other countries grew exponentially, highlighting the South-South Cooperation (SSC). On SSC, successful experiences in country in the South serve as an example for others. However, the actual crisis will have effects on international cooperation and we intend to investigate the role of Brazilian CSS in the last decade and what the probably effects of the crisis will be, through bibliographic review and available data.
\end{abstract}

Keywords: International Cooperation; South-South Cooperation; Public Policies.

\footnotetext{
${ }^{\text {a }}$ Professora na Universidade Anhembi Morumbi. Pós-doutorado no IERI da Universidade Federal de Uberlândia. E-mail: pandrade.eco@gmail.com.

b Professor na Universidade Federal de Uberlândia. E-mail: nafilho@ufu.br.
} 


\section{Introdução}

Ao observar historicamente a inserção brasileira na geopolítica mundial é notável que, segundo Amorim (2007) e Soares de Lima (2005), o país tenha optado por uma atuação em que a negociação diplomática prevalece na resolução dos conflitos. Esse processo foi facilitado através da própria localização do país, uma vez que o hemisfério ocidental se configura como uma das regiões de maior poder de decisão, e (com exceção da Segunda Guerra Mundial), configura-se também com a ausência de conflitos expressivos com a política externa americana, se comparado com países do Oriente Médio, asiáticos, entre outros. Além disso, desde o final do século XIX, o Brasil apresenta uma inserção regional consideravelmente estável, com ausência de conflitos territoriais na América Latina, inclusive se autodenominando "geopoliticamente satisfeito".

Ainda segundo Soares de Lima (2005), essa característica pacífica da inserção brasileira retirou, especialmente das elites brasileiras, a preocupação com a segurança do país, concentrando-se nas questões de ordem econômica, especialmente através das alianças comerciais. Guimarães (2013) aprofunda essa análise mostrando como esse tipo de inserção corresponde a uma característica dos países periféricos que podem se apresentar na dinâmica internacional de três maneiras: a) buscando se promover de forma autônoma aos países desenvolvidos (resistindo às pressões permanentes); b) realizando alianças através de acordos de livre comércio ou; c) por meio da integração pelo surgimento de blocos de Estados, ainda que liderados pelos países desenvolvidos.

Nesse sentido, é evidente que o Brasil optou pelas duas últimas opções, se subordinando aos interesses das grandes potências, em especial dos americanos, uma vez que, segundo Pecequilo (2012, p. 4), desde 1902 a política externa tinha como foco as Américas e especialmente "o alinhamento automático e o pragmático aos Estados Unidos (...) caracterizado pelo predomínio do eixo Norte-Sul, estando associado aos conceitos de cooperação vertical e Primeiro Mundo".

Ainda segundo a mesma autora, foi somente com a chegada da Era Vargas que o país passou a promover um modelo multilateral nas suas questões internacionais, culminando em um novo padrão de política externa, o chamado "paradigma multilateral-global”, colocando foco no eixo de cooperação entre os países do Sul e buscando a consolidação econômica através da política externa. A chegada dos governos autoritários na maioria dos países latino-americanos no final dos anos 1960 promoveu um recuo na tentativa de imersão desses países no cenário internacional, uma vez que muitos deles obtiveram apoio dos americanos para chegar ao poder. Particularmente no Brasil, esse processo foi aprofundado após a democratização, especialmente em períodos de crise econômica, como por exemplo nos anos 1990, através da adoção das recomendações do Consenso de Washington e de todos os 
preceitos do neoliberalismo, bem como um alinhamento expressivo aos Estados Unidos através da abertura comercial e da desregulamentação, entre outras medidas.

Somente após a estabilidade monetária no início dos anos 2000 que o Brasil retomou as atividades relacionadas ao eixo de cooperação entre os países do Sul e, segundo Amorim (2007), ex-ministro das relações exteriores no governo do expresidente Luís Ignácio Lula da Silva, foi durante o seu mandado que ficou evidente o reconhecimento da América do Sul como um local a ser gerado uma vertente regional de desenvolvimento sul-americano como prioridade, especialmente no aprofundamento do Mercosul e na consolidação da União Sul-Americana. Nesse sentido, ainda segundo o ex-ministro, "o Brasil é defensor intransigente de soluções pacíficas e tem manifestado preferência pela via multilateral para resolver os conflitos [...]. O multilateralismo encontra nas Nações Unidas sua mais legítima expressão" (AMORIM, 2007, p. 8).

Segundo Mello (2011) e Milani (2012), o país detém importante participação em negociações, em assembleias e no Conselho de Segurança da ONU desde a Segunda Guerra Mundial. Entretanto, especialmente após $1994^{1}$ com o surgimento da Agenda para o Desenvolvimento, ficou clara e ampliada a importância que as Nações Unidas colocaram na chamada Cooperação Internacional para o Desenvolvimento (CID). Ainda segundo Milani (2012), esse tipo de cooperação busca a promoção do desenvolvimento em bases solidárias para enfrentar os dilemas e as desigualdades geradas pelo sistema capitalista.

Nesse cenário, o Brasil, através da iniciativa Fome Zero e, posteriormente, dos resultados reconhecidos internacionalmente no combate à fome e à pobreza pela sua política social - vale salientar que, segundo Silva (2017), a pobreza extrema no país diminuiu de $16,4 \%$ para 4,7\% e o Î́ndice de Gini caiu de o,570 para 0,515 entre 2004 e 2014 - chamou a atenção da própria ONU e colocou o país em destaque. Unido a isso, segundo o ex-ministro Amorim (2007, p. 12), o país ensejava uma posição permanente no Conselho de Segurança da ONU, pois "tal como existe hoje, o Conselho é incapaz de articular uma visão equilibrada e inclusiva da ordem internacional, que reflita de forma satisfatória as percepções do mundo em desenvolvimento".

Sendo assim, o governo brasileiro buscou se destacar cada vez mais internacionalmente através do combate à pobreza e desigualdade (sem abandonar os diversos acordos comerciais realizados historicamente e especialmente com os

\footnotetext{
${ }^{1}$ É necessário destacar que, nos anos 1990, as medidas neoliberais colocadas em prática na maioria dos governos latino americanos obtiveram como resultado um aumento expressivo da desigualdade e da pobreza, chamando a atenção dos organismos internacionais para essa temática, com destaque para as Nações Unidas.
} 
países desenvolvidos) e, em conjunto, buscou colocar em prática iniciativas que fortalecessem a integração regional dessa temática, surgindo o maior incentivo a uma Cooperação Sul-Sul (CSS).

Burges (2012) mostra que a CSS nasce dos esforços de promoção da CID, no entanto, com o foco da sua promoção nos países da América do Sul, sendo o Brasil o agente com maior representatividade. Segundo o mesmo autor, enquanto os membros ligados a tradicional ajuda comunitária internacional permaneceram fornecendo ajuda bilateral em valores monetários, os países emergentes surgiram como potenciais "doadores" e se tornaram relevantes para a oferta de empréstimos, a assistência técnica, os investimentos estrangeiros, entre outros.

Os resultados obtidos a partir dessas ações foram compilados por relatórios realizados pelo Instituto de Pesquisa Econômica Aplicada (Ipea) em conjunto com a Agência Brasileira para a Cooperação (ABC), com o objetivo de analisar fundamentalmente a CDI brasileira, um marco na análise de políticas públicas visto que até então nenhum outro documento dessa envergadura havia sido realizado. Em relação a CDI, os relatórios demonstram que o país atuou em 159 países, com despesas próximas a R\$2,8 bilhões (cerca US\$ 1,5 bilhão) entre 2011 e 2013, com a predominância de dispêndios com organismos internacionais (mais de 50\%) (IPEA e $A B C$, 2016). O mesmo relatório ainda evidencia que houve "mobilização de servidores na difusão de práticas brasileiras bem-sucedidas; a formação de pessoal estrangeiro por meio da concessão de bolsas de estudo e oferta de vagas em instituições de ensino no Brasil, entre outras medidas" (IPEA; ABC, 2016, p. 17).

No entanto, é perceptível que após a crise econômica e política instaurada no país com o impeachment da ex-presidenta Dilma Rousseff em 2016, o novo governo não colocou em nenhum ponto do seu plano de atuação² a preocupação com a CDI ou CSS, focando somente na questão dos acordos comerciais e do Mercosul. Essa atitude evidencia que a CSS brasileira é uma política atrelada aos interesses do governo na situação, e provavelmente continuará dependente da gestão governamental para se desenvolver, aumentando as chances de interrupções e reversões na política.

Sendo assim, o presente trabalho tem como objetivo principal demonstrar que a Cooperação Sul-Sul (CSS) realizada pelos Governos Lula configura-se como uma inovação na política de cooperação brasileira, tendo como hipótese fundamental que esa reorientação, se não foi suficiente para proporcionar ao Brasil uma cadeira permanente no Conselho de Segurança da ONU, foi capaz de ampliar o escopo da cooperação de modo a localizar o Brasil como uma referência regional,

\footnotetext{
${ }^{2}$ O plano de governo "Uma Ponte para o Futuro" pode ser acessado em: <https://www.fundacaoulysses.org.br/wp-content/uploads/2016/11/UMA-PONTE-PARA-OFUTURO.pdf>
} 
especialmente para os países do eixo Sul. Para tanto, o artigo será dividido nas seguintes seções, além da introdução: a) CID e CSS: Aspectos teóricos e o destaque no Brasil; b) CDI e CSS brasileira: Resultados e gestão; c) (Possíveis) Efeitos da atual crise sobre a CDI e CSS; d) Considerações Finais e e) Referências Bibliográficas.

\section{CID e CSS: Aspectos Teóricos e o Destaque no Brasil}

Ao observar a política internacional, Guimarães (2013) chama a atenção para o predomínio de grandes potências, lideradas pelos Estados Unidos, que também participam ativamente das decisões tomadas pela ONU. No sistema internacional encontramos alguns agentes representativos, entre eles os estruturantes, que compõe os Estados e os blocos de Estados; os organismos multilaterais; as megaempresas; as Organizações Não Governamentais (ONGs); as legislações nacionais e os acordos internacionais, que articulam todo o sistema.

Ainda segundo o mesmo autor, esse espectro se configurou de forma histórica e continua definindo grupos de Estados no sistema mundial, sendo eles:

a) Os Estados Unidos, os países industrializados da Europa Ocidental, metrópoles de antigos impérios, os Estados ex-socialistas da Europa Oriental, o Canadá, a Austrália, a Nova Zelândia, o Japão e a Coreia do Sul, países esses que foram os primeiros integrantes da Organização para Cooperação e Desenvolvimento Econômico (OCDE);

b) Os Estados subdesenvolvidos, especialmente as ex-colônias na América Latina, na África e na Ásia, com baixo grau de industrialização, pouco dinamismo tecnológico, muitos recursos naturais etc.;

c) Três grandes Estados: Índia, China e a Rússia, onde as duas primeiras estão em desenvolvimento acelerado e comportam um terço da população mundial, todos possuem armas nucleares, projeção política expressiva regionalmente, entre outros.

Essa divisão não abrange alguns países que começam a se destacar internacionalmente nas últimas décadas, como por exemplo Singapura e a Malásia, porque eles ainda obtêm pouca expressividade política.

Em tese, imagina-se que esses países realizam trocas dentro desse sistema internacional com o objetivo de promover maior segurança, desenvolvimento e inclusive a paz mundial. Entretanto, Guimarães (2013, p. 12) salienta que apesar de alguns avanços realizados em alguns períodos históricos nessa direção, de maneira geral, a política internacional "não tem como objetivos a paz, a cooperação e a segurança da humanidade como um todo. Essa dinâmica, atual herdeira da evolução do sistema internacional nos últimos cinco séculos, se encontra ainda organizada de forma imperial". 
Nesse sentido, sob a égide do imperialismo, é notável nesse ambiente a existência de relações de pressão, antagonismo, tensões, cooperações e inclusive agressão, a depender dos interesses dos grupos de Estados em cada momento. De acordo com essa lógica, o primeiro grupo de Estados tem como objetivo maior consolidar sua liderança e privilégio, enquanto que o segundo grupo busca despontar de forma autônoma e o terceiro desafia a ordem vigente imposta pelos Estados Unidos, especialmente após a Segunda Guerra Mundial.

O Brasil, diante dessa disputa internacional, detém certas especificidades que o fazem ser historicamente presente nas negociações internacionais e, entre elas segundo Guimarães (2013), destacam-se a sua localização geográfica, importância regional e dimensão territorial no continente americano, fazendo com que os Estados Unidos nos considerem uma importante área de influência.

Sendo assim, é impossível que o Brasil não participasse da política internacional, uma vez que desde 1900 o país já atuava no sentido de consolidar suas relações com a América do Norte, especialmente através do alinhamento submisso ao eixo Norte-Sul. Segundo Pecequilo (2012, 2008), os questionamentos acerca dessas relações remontam aos anos 1960 através de um conjunto de transformações pelas quais perpassou o país interna e externamente. No campo interno, o processo de substituição de importações desde a década de 1930 impulsionou o país, tornando-o mais complexo econômica e socialmente e, na área externa, desde a Guerra Fria vem se alterando os padrões relativos à distribuição de poder entre os grupos de Estados internacionais, modificando a bipolaridade verificada entre americanos e soviéticos, obtendo os primeiros passos para uma maior multipolaridade internacional.

Entretanto, esses movimentos remontam desde após a Segunda Guerra Mundial, pois conforme aponta Almino (2017), o fim da guerra impulsionou as Nações Unidas com o objetivo de reconstruir os países afetados e também o de acelerar o desenvolvimento dos menos industrializados, fazendo com que desde a década de 1970 alguns países emergentes elaborassem alguns preceitos de cooperação entre eles, o que posteriormente ficou conhecida como a cooperação horizontal, em contraposição a cooperação Norte-Sul (cooperação vertical). Mello (2011) também corrobora essa tendência, no entanto, chama a atenção novamente para a importância do período da Guerra Fria especialmente para o Brasil, uma vez que:

(...) nos marcos da Guerra Fria, foi nos foros de natureza econômica e na atuação no eixo Norte-Sul que a diplomacia multilateral brasileira encontrou espaço privilegiado para o exercício de uma atuação protagônica, conferindo a política externa a missão de complementar as políticas nacionais de desenvolvimento industrial (MELLO, 2011, p. 9). 
Conforme reafirma Milani (2012), a Guerra Fria institucionalizou o multilateralismo voltado a uma Cooperação Internacional para o Desenvolvimento (CID), pois foi somente devido as ameaças soviéticas que os EUA iniciaram seus programas de ajuda internacional voltados ao desenvolvimento. Ainda segundo o mesmo autor, a CID tem como objetivo promover "diálogos sobre políticas públicas ("policy dialogues"), ao critério da seletividade (com foco nas políticas econômicas) e a programas de formação ("capacity-building") [...], ou seja, da "ajuda internacional” passou-se à lógica de cooperação e parcerias” (MILANI, 2012, p. 214).

Ao observar o caso brasileiro, Mello (2011) constata que foi do final dos anos 1980 ao início dos 1990 que a aspiração brasileira a um assento permanente no Conselho de Segurança da ONU foi expressa nos foros multilaterais. Um fator institucional marcante nesse período é a criação da Agência Brasileira de Cooperação (ABC) ainda em 1987 e, conforme menciona Lima (2017), o decreto de criação da agência informa que a mesma obtinha como objetivo principal realizar programas de cooperação técnica em diversas áreas do conhecimento e que envolvessem organismos internacionais em outros países, com clara promoção de projetos que buscassem um novo patamar de desenvolvimento, ou seja, a promoção da CID.

Desde então até os dias atuais, a CID brasileira vem crescendo em conjunto com o próprio desenvolvimento da $\mathrm{ABC}$ que, em 2017, completou 30 anos de existência. É notável que os esforços de integração regional realizados colocaram ênfase a um tipo de cooperação em específico: a Cooperação Sul-Sul (CSS), uma CDI voltada aos países do eixo Sul.

A CSS, segundo Milani (2012, p. 224) busca:

(...) introduzir uma nova visão do desenvolvimento econômico dos países em desenvolvimento (quanto ao papel do Estado, em matéria de alianças entre países do Sul, quanto ao princípio da não intervenção, à defesa da horizontalidade dos programas de cooperação, etc.) e garantir uma inserção internacional diferenciada de alguns países do Sul no diálogo com os países desenvolvidos (Chisholm, L.; Steiner-Khamsi, 2009). Boa parte do argumento político que sustenta a CSS se fundamenta no pressuposto de que países em desenvolvimento podem e devem cooperar a fim de resolver os seus próprios problemas políticos, econômicos e sociais com base em identidades compartilhadas (ex-colônias, status econômico, experiência histórica etc.)

Chediek (2017) salienta que um dos marcos institucionais relevantes para a CSS foi a Conferência de Bandung, realizada em 1955, na qual despontou a expressão “Terceiro Mundo", gerando representatividade mundial para esse conjunto de 
países. Desde então vem crescendo a relevância da CDI e da CSS para a ONU, uma vez que em 1972, na sua Assembleia Geral da ONU foi gerado o "Grupo de Trabalho sobre Cooperação Técnica entre os Países em Desenvolvimento (CTPD)", com o objetivo de integrar a CSS no Programa das Nações Unidas para o Desenvolvimento (PNUD).

Observando as práticas brasileiras em relação à CSS, Milani (2012) demonstra que elas se elevaram após os anos 2000 e buscaram distinguir-se das demais práticas de CDI, utilizando como metodologia o instrumento de cooperação técnica, em consonância com a CTPD das Nações Unidas. Essa metodologia tem como foco a transferência de conhecimentos, experiências de sucesso e equipamentos, contribuindo assim para capacitar os recursos humanos e as instituições do país receptor, elevando o poder de autonomia dos receptores frente ao desenvolvimento de suas próprias políticas.

Dessa forma, chegamos aos anos 2000 e é importante destacar nesse período duas tendências que aconteceram simultaneamente e foram retroalimentadas: no campo interno: o destaque das políticas sociais e a diminuição da pobreza e da desigualdade e, no campo externo: o fortalecimento de laços e parcerias com diversas instâncias e agências da ONU. Em relação ao primeiro caso, pesquisadores como Osório (2015) e Souza (2012) mostram que o crescimento da renda dos 20\% mais pobres foi de $127 \%$ entre 1995 e 2009 , fazendo com que a pobreza extrema durante esse período passasse de $16,4 \%$ para $4,7 \%$ da população brasileira, ao mesmo tempo em que o Índice de Gini caiu de o,599 para o,539 e o crescimento real do PIB em 2010 passou a marca dos $7 \%$, configurando um cenário positivo, conforme demonstra a Tabela 1.

Tabela 1: Média da Renda Domiciliar per capita, Brasil 2004-2014

\begin{tabular}{c|c|c}
\hline \hline Ano & \multicolumn{2}{|c}{ US\$/dia (PPC, dezembro, 2011) } \\
\hline & Média & Erro (I.C. 95\%) \\
\hline 2004 & US\$ 11,13 & $+/-$ o,23 \\
\hline 2005 & US\$ 11,80 & $+/-0,25$ \\
\hline 2006 & US\$ 12,91 & $+/-0,27$ \\
\hline 2007 & US\$ 13,27 & $+/-0,27$ \\
\hline 2008 & US\$ 13,89 & $+/-0,27$ \\
\hline 2009 & US\$ 14,28 & $+/-0,27$ \\
\hline 2011 & US\$ 15,14 & $+/-0,27$ \\
\hline 2012 & US\$ 16,33 & $+/-0,33$ \\
\hline 2013 & US\$ 16,92 & $+/-0,31$ \\
\hline 2014 & US\$ 17,44 & $+/-0,32$ \\
\hline \hline
\end{tabular}

Fonte: Osório (2015) 
Após 2010, ainda ao observar a Tabela 1, é nítido que o rendimento médio da renda domiciliar continua progressivamente a subir até 2014, fato também ilustrado por Silva (2017), uma vez que o Î́ndice de Gini chegou a seu menor valor registrado nessa série, alcançando 0,515 em 2014. Esses resultados foram alcançados especialmente após a chegada do ex-presidente Lula ao poder e obtiveram continuidade até o primeiro mandato da ex-presidenta Dilma Rousseff, uma vez que já no primeiro plano de governo o objetivo fundamental estava em crescer reduzindo as desigualdades sociais e regionais, gerando um novo perfil de gestão e articulação de políticas públicas (Brasil, 2003). Essa intenção começou a ser materializada a partir da criação do Ministério do Desenvolvimento Social (MDS) em 2004, pasta criada exclusivamente para a promoção de programas e projetos ligados à política social, com destaque para o Bolsa Família.

Durante esse período também foi reconhecido por diversos pesquisadores a elevação da participação das políticas públicas, com destaque para a política social. Silva (2017) analisou o perfil de gastos nessa área de acordo com os dados disponibilizados pelo Tesouro Nacional (2016) e, segundo a Tabela 2, a elevação nas despesas foi superior a 3 pontos percentuais do PIB ao se comparar os valores observados entre 2002 e 2015, com destaque para as seguintes áreas: a) Educação e Cultura (com elevação de o,74 p.p. do PIB); b) Assistência Social (o,78 p.p. do PIB) e c) Previdência Social (com o,97 p.p. do PIB).

\section{Tabela 2: Evolução do Gasto Social do Governo Central, Brasil, 2002 a 2015 (\% do PIB)}

\begin{tabular}{|c|c|c|c|c|c|c|c|c|c|c|c|c|c|c|}
\hline Categorias & 02 & 03 & 04 & O5 & 06 & 07 & 08 & 09 & 10 & 111 & 12 & 13 & 14 & 15 \\
\hline Assist. Social & 0,5 & 0,6 & 0,8 & 0,9 & 1,0 & 1,0 & 1,0 & 1,3 & 1,3 & 1,3 & 1,4 & 1,5 & 1,5 & 1,5 \\
\hline $\begin{array}{c}\text { Educação e } \\
\text { Cultura }\end{array}$ & 1,7 & 1,6 & 1,5 & 1,6 & 1,6 & 1,7 & 1,8 & 2,0 & 2,1 & 2,2 & 2,3 & 2,3 & 2,6 & 2,7 \\
\hline Organ. Agrária & 0,2 & 0,2 & 0,3 & 0,3 & 0,3 & 0,3 & 0,2 & 0,2 & 0,1 & 0,2 & 0,1 & 0,1 & 0,1 & 0,2 \\
\hline $\begin{array}{c}\text { Previdência } \\
\text { Social }\end{array}$ & 8,0 & 8,2 & 8,3 & 8,9 & 8,9 & 8,6 & 8,3 & 8,9 & 8,5 & 8,4 & 8,7 & 8,7 & 8,9 & 9,3 \\
\hline $\begin{array}{l}\text { Saneam. e } \\
\text { Habitação }\end{array}$ & 0,1 & 0,1 & 0,1 & 0,1 & 0,1 & 0,1 & 0,2 & 0,2 & 0,2 & 0,3 & 0,4 & 0,4 & 0,5 & 0,5 \\
\hline Saúde & 1,8 & 1,6 & 1,8 & 1,7 & 1,8 & 1,8 & 1,8 & 2,0 & 1,9 & 1,9 & 2,0 & 2,0 & 2,1 & 2,1 \\
\hline $\begin{array}{c}\text { Trabalho e } \\
\text { Emprego }\end{array}$ & 0,5 & 0,5 & 0,5 & 0,6 & 0,7 & 0,7 & 0,7 & 0,9 & 0,8 & 0,8 & 0,8 & 0,9 & 1,4 & 1,2 \\
\hline Total & 12,8 & 12,6 & 13,2 & 13,9 & 14,2 & 14,2 & 14,1 & 15,4 & 14,9 & 15,0 & 15,8 & 15,8 & 17,0 & 17,5 \\
\hline
\end{tabular}

Fonte: Silva (2017)

Apesar dos avanços conquistados, conforme apontam Marques e Mendes (2007) e Carvalho (2018), é importante mencionar que os governos petistas realizaram avanços sociais significativos, entretanto "serviram a dois senhores" na medida em que a política econômica e monetária não foi alterada e reformas 
estruturais também não foram realizadas, gerando um cenário em que a própria política social ficou dependente da ação governamental (caráter de política de governo), ou seja, após o impeachment da ex-presidenta, a manutenção dos avanços conquistados dependerá dos esforços realizados pelo governo interino que, comprovadamente através de seu plano de governo, aponta para a direção contrária.

Por outro lado, os projetos desenvolvidos nessa área despertaram o interesse dos gestores internacionais em conhecer a experiência brasileira de combate à pobreza e à desigualdade. Segundo Hirst (2012), conforme os países emergentes obtêm maior participação em termos geopolíticos e econômicos mundialmente, os mesmos tendem a gerar novas fontes de pressões que elevam as suas responsabilidades, especialmente com os demais países em condições similares, seja para melhorar a provisão de bens públicos (incluso as políticas públicas) ou para oferecer ajuda humanitária.

O destaque da política social (inclusive a sua dependência à plataforma de governo vigente) também pode ser verificada no âmbito externo, através da articulação de diversas ações em conjunto do governo brasileiro e das agências da ONU. O relacionamento entre o Brasil e as Nações Unidas se intensificou após a Segunda Guerra Mundial e após os incentivos ao multilateralismo. Porém, especialmente nos anos 2000, há uma série de fatores que desencadearam esse estreitamento, com destaque para o surgimento dos Objetivos de Desenvolvimento do Milênio (ODM) que posteriormente se transformaram nos Objetivos de Desenvolvimento Sustentável (ODS), os quais atualmente contemplam a Agenda 2030 para o Desenvolvimento. Como explica o site do PNUD³, dezoito anos atrás, durante a Cúpula do Milênio da ONU, 189 nações e 23 organizações internacionais se comprometeram com uma série de objetivos e metas para a melhoria das condições de vida das populações mais pobres do planeta, compromisso conhecido como os ODM, divididos em 8 prioridades a serem conquistadas até 2015. Os resultados dessa iniciativa foram singulares na história da ONU, com destaque para a diminuição pela metade no número de pessoas que vivem na extrema pobreza no mundo. Após esse avanço, foi desenvolvida uma nova agenda (chamada Agenda 2030), com objetivos mais amplos e inclusivos, o chamado Objetivos de Desenvolvimento Sustentável ${ }^{4}$ (ODS) que tem como meta fundamental erradicar a pobreza em todas as suas formas até 2030, contemplando as dimensões econômica, social e ambiental através de 17 áreas prioritárias.

\footnotetext{
3 Acesso a reportagem em: < https://nacoesunidas.org/pnud-explica-transicao-dos-objetivos-domilenio-aos-objetivos-de-desenvolvimento-sustentavel/>

4 Maiores informações acerca das metas a serem alcançadas em:

<https://nacoesunidas.org/pos2015/agenda2030/>
} 
Segundo Chediek (2017), a CSS é referida como um instrumento relevante para alcançar os ODS pela própria ONU, uma vez que existe uma clara inclusão das prioridades dos países emergentes nessa agenda global. Nesse sentido, a divulgação de boas práticas de desenvolvimento entre países do Sul para o Sul, deverá gerar debates internacionais significativos, gerando colaboração mútua entre os países. Ainda segundo o mesmo autor, a concretude desse pensamento foi a Conferência de Alto Nível das Nações Unidas sobre a Cooperação Sul-Sul realizada em Nairóbi em 2009, incentivando o sistema das Nações Unidas para essa temática e invocando os Estados membros a desenvolver iniciativas de CSS e de cooperação triangular (CHEDIEK, 2017);

Todas essas iniciativas poderiam ser realizadas sem ameaçar as demais iniciativas de cooperação (entre elas a Norte-Sul), especialmente aquelas relacionadas ao comércio exterior. Inclusive, após a crise internacional de 2008 , segundo Mello (2011), o Brasil assume posição de destaque no grupo dos 20 países mais ricos do mundo ( $\mathrm{G} 2 \mathrm{O})$, gerando inclusive (ainda que de forma informal) alguma mudança na governança internacional através de um grupo maior de países do que o apresentado pelo antigo grupo dos oito países mais ricos do mundo (G8).

Sendo assim, é notável que o ex-presidente Lula obtinha em seu mandato características relevantes para que colocasse em evidência o país internacionalmente. Uma dessas características é a sincronia dos objetivos internos do país (especialmente o combate à pobreza extrema) com os ODS e as Nações Unidas; seguida de maior incentivo para a CSS e do desejo de conquistar a cadeira permanente no Conselho de Segurança da ONU. Além disso, segundo Amorim (2007), outras características seria a da possibilidade de colocar o enfoque nessas questões sem modificar a cooperação internacional com os países do Norte, especialmente os tratados comerciais, assegurando mais uma vez seu papel conciliador e submisso frente aos Estados Unidos.

Portanto, conforme apontam Mello (2011) e Amorim (2007), a CSS torna-se um tema prioritário na agenda da política externa a partir do governo Lula, desencadeando contatos bilaterais com outros países do eixo Sul, inclusive com a criação (em 2004) de um órgão especifico no Itamaraty para coordenar ações de combate à fome em outros países, a "Coordenação-Geral de Cooperação Humanitária e Combate à Fome (CGFome)". A próxima sessão irá explorar os resultados obtidos até o momento para que, posteriormente, seja possível avaliar os efeitos da crise atual nessa temática.

\section{CDI e CSS Brasileira: Resultados e Gestão}

Como demonstrado anteriormente, a CDI e a CSS no Brasil foram colocadas em evidência especialmente nas plataformas de governo nos anos 2000, utilizando 
especialmente da cooperação técnica como metodologia fundamental. Em relação à $\mathrm{CDI}$, os estudos mais recentes acerca dos resultados remontam da parceria entre $o$ IPEA e a ABC em 2010.

A primeira publicação, que analisa o período entre 2005 e 2009, obteve como metodologia fundamental em seu levantamento "a totalidade de recursos investidos pelo governo federal brasileiro, totalmente a fundo perdido, no governo de outros países, em nacionais de outros países em território brasileiro, ou em organizações internacionais com o propósito de contribuir para o desenvolvimento internacional" (IPEA e ABC, 2010, p. 12). Ainda de acordo com essa pesquisa, o volume total investido nesses 5 anos foi de R\$2.898.526.873,49 (cerca de US\$ 1,43 bilhão), estratificado em: ajuda humanitária, bolsa de estudo para estrangeiro, cooperação técnica, científica, tecnológica e as contribuições para organizações internacionais (IPEA; ABC, 2010).

Ainda segundo a mesma pesquisa, "a cooperação praticamente dobra entre 2005 e 2009, passando de R\$ 384,2 milhões para mais de R\$ 724 milhões, respectivamente". (IPEA; ABC, 2010, p. 19). Conforme demonstra a tabela 3, os itens referentes à assistência humanitária e a cooperação técnica aumentaram de 7,53\% do total em 2005 para 25,51\% do total em 2009, indicando uma sextuplicação de recursos aplicados, evidenciando o destaque que o governo brasileiro concedeu à CDI, bem como ao desenvolvimento de programas e projetos com organismos internacionais, correspondendo a cerca de $70 \%$ dos dispêndios totais no período.

Tabela 3: Cooperação Brasileira para o Desenvolvimento Internacional 2005-2009 (\% em relação ao total)

\begin{tabular}{c|c|c|c|c|c}
\hline \hline Categorias & $\mathbf{2 0 0 5}$ & $\mathbf{2 0 0 6}$ & $\mathbf{2 0 0 7}$ & $\mathbf{2 0 0 8}$ & $\mathbf{2 0 0 9}$ \\
\hline Assistência Humanitária & 0,3 & 0,9 & 5,6 & 4,8 & 12,0 \\
\hline Bolsa de Estudo para Estrangeiro & 14,6 & 9,3 & 9,9 & 11,5 & 6,1 \\
\hline $\begin{array}{c}\text { Cooperação Técnica } \\
\text { Contribuições para Organismos } \\
\text { Internacionais }\end{array}$ & 7,2 & 5,4 & 6,2 & 9,5 & 13,5 \\
\hline Total & 100 & 100 & 100 & 100 & 100 \\
\hline \hline
\end{tabular}

Fonte: IPEA e ABC (2010)

Em relação às contribuições para os organismos internacionais, o estudo ainda destaca as contribuições para os fundos regionais, forte contribuição à CSS. Nesse sentido, menção especial foi reservada ao Fundo de Convergência Estrutural e de Fortalecimento Institucional do Mercosul (Focem), totalizando mais de 30\% do total das contribuições aos organismos internacionais. Esse fundo, criado em 2004 pelos membros do bloco, tem como objetivo enfrentar as assimetrias da região para elevar a competitividade dos países e das regiões menos favorecidas. Outras 
contribuições relevantes para a CSS estão nas capitalizações dos fundos de bancos regionais, sendo "a finalidade precípua desses recursos, nos três casos, Banco Mundial, Banco Interamericano de Desenvolvimento (BID) e Banco Africano de Desenvolvimento (BAD), a de contribuir com o crescimento econômico e com a redução da pobreza nos países de renda baixa". (IPEA e ABC, 2010, p. 22).

Uma nova pesquisa acerca desse tema foi publicada em 2016, analisando o período entre 2011 e 2013, período no qual o volume de recursos destinado à CDI perde força relativa em relação aos anos anteriores. No entanto, os pesquisadores afirmam que "o volume dos recursos gastos, em especial até 2010, acabou levando a interpretações exageradas sobre o novo perfil do país no campo da CID, recomendando cautela" (IPEA e ABC, 2016, p. 16). Os valores brutos, em reais, ultrapassam os R \$ 985 milhões em 2011 para cerca de R 1 bilhão em 2012 e, por fim, aproximadamente 857 milhões em 2013 (em dólares esses valores são, aproximadamente, US\$ 588 milhões em 2011 para US\$ 396 milhões em 2013) (IPEA e $\mathrm{ABC}$, 2016).

Ainda segundo o mesmo estudo e o Gráfico 1, continuou o predomínio das contribuições feitas às organizações internacionais (56\% do total), evidenciando a preferência por uma atuação multilateral, ao mesmo tempo que a cooperação técnica e a ajuda humanitária também perdem participação durante o período.

\section{Gráfico 1: Dispêndios do governo brasileiro com a Cooperação para o Desenvolvimento Internacional, 2011-2013 (em \%).}

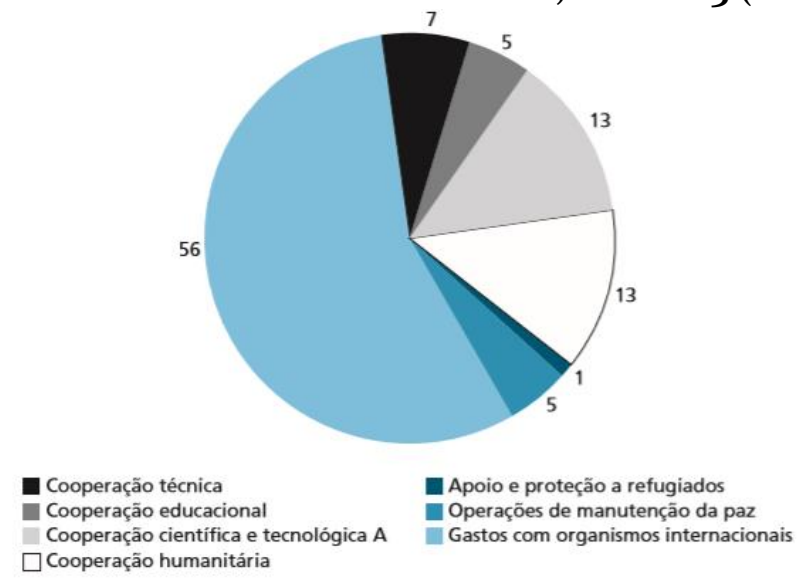

Fonte: IPEA e ABC (2016)

Especificamente em relação à CSS, o relatório informa que foi gerado um Fundo Fiduciário de Cooperação Sul-Sul em conjunto com o Banco Africano de Desenvolvimento, estabelecendo a estrutura necessária para o compartilhamento de tecnologia, conhecimento e recursos entre os países em desenvolvimento. Com isso, o Brasil efetuou uma contribuição total de US\$ 6 milhões entre 2011 e 2013, que se 
transformaram efetivamente em $\mathrm{R} \$ 11,8$ milhões, sendo que esses valores foram distribuídos para custear 14 projetos em diversas áreas, com destaque para a agricultura, a governança e o desenvolvimento social (IPEA e ABC, 2016).

Através desses estudos é notável a necessidade de continuação na avaliação da CDI e CSS no Brasil, uma vez que claramente o país realizou um esforço orçamentário, administrativo, acadêmico e diplomático significativo nessa área, especialmente entre 2005 e 2010 . Chediek (2017) também alerta para a dificuldade de quantificar os valores compartilhados através da troca de experiências, habilidades etc., que podem ter alcançado, entre 2005 e 2010, cerca de US\$ 2,1 bilhões segundo dados do PNUD.

Com dificuldade de obter dados e avaliações em relação à cooperação internacional, os dados sobre ela no Brasil são ainda mais escassos e, em sua maioria, relativos à CDI (uma vez que ela integra a própria CSS). Chediek (2017, p. 55), novamente reafirma a contribuição não-financeira da CSS brasileira, pois:

O princípio da solidariedade, presente no cerne da CSS e encontrado no discurso oficial do país desde o governo de Fernando Henrique Cardoso, ganhou centralidade durante o governo Lula (ibid.). Além disso, é possível vincular a importância atribuída à solidariedade com o caráter pacifista e tradicional da política externa do Brasil, a disposição para projetar o soft power e a manutenção de laços amistosos com outros países. Dada a relevância da solidariedade na CSS, cabe ressaltar que o país tem esse princípio como parte de seu discurso oficial, uma vez que envia uma mensagem clara ao mundo sobre como o país pretende se posicionar na esfera internacional.

Para além do aspecto financeiro, é importante analisar como é realizada a gestão dos projetos de CSS e quais os principais parceiros internacionais e programas implementados atualmente. Em relação à gestão, o Manual de Gestão da Cooperação Técnica Sul-Sul elaborado pela ABC (2013) mostra que a CSS brasileira atua principalmente: a) no apoio à mobilização de agentes e capacidades dos países parceiros; b) no intercâmbio de métodos, abordagens, experiências, entre outros; c) nas ações de fortalecimento organizacional e d) na identificação e mobilização para gerar parcerias internas e externas, além de arranjos interinstitucionais.

A operacionalização da cooperação, ainda segundo ABC (2013), é realizada através da implementação técnica (refere-se às ações de efetiva cooperação que envolvam transferência ou à aplicação de conhecimentos etc., entre os cooperantes) e sua execução administrativo-financeira (designada para indicar procedimentos e atividades necessárias para que os produtos esperados sejam alcançados). No caso 
da implementação técnica, a mesma pode ser realizada através de 4 instrumentos: a) Programa: conjunto de iniciativas com objetivos comuns que são realizadas e coordenadas de forma centralizada, porém sua execução é realizada separadamente com ou sem prazo definido; b) Projeto: iniciativa de prazo definido que abarca um conjunto de atividades; c) Ação Preparatória: Promove os requisitos operacionais e técnicos necessários para a prospecção e formulação de projetos ou programas de CSS e d) Ação Simplificada: iniciativas realizadas obrigatoriamente no curto prazo, através de ações pontuais e que não exijam um complexo escopo técnico.

Os arranjos para a execução administrativa-financeira podem ser: a) Execução pelo governo brasileiro: quando o país assume a execução das iniciativas no que tange a área administrativa e financeira; b) Execução paralela: quando é de responsabilidade paralela entre o governo brasileiro e a outra entidade parceira, como organismos internacionais ou agências de cooperação de outros países com recursos que são provenientes de ambas as partes, com cada uma executando a sua parte em uma coordenação conjunta; ou c) Execução descentralizada: quando outra entidade que não o governo brasileiro é responsável pela execução administrativafinanceira e os recursos podem ou não ser provenientes do governo brasileiro, uma vez que o mesmo se mantenha como coordenador das ações. A estrutura lógica que permeia a construção de um projeto ou programa tem como elementos básicos a existência de objetivos de desenvolvimento, objetivos específicos e os resultados esperados e, para alcançar os resultados, são necessários os insumos para a realização das atividades e produtos $(A B C, 2013)$.

Ainda segundo a $A B C$ (2013), os principais atores que participam da cooperação técnica são: a) Instituições Cooperantes: entidades dos países envolvidos diretamente na implementação técnica ou execução administrativo-financeira, sendo possível que elas se coincidam com os beneficiários diretos, especialmente em projetos voltados para implementar ou desenvolver capacidades organizacionais; $b$ ) Beneficiários: indivíduos ou instituições que se beneficiam do projeto implementado, sendo subdivididos em beneficiários diretos ou indiretos e; c) Outras partes interessadas: instituições locais, legislativo, judiciário, associações comunitárias, mídia ou outros que tenham interesse em encontrar uma solução para o problema apresentado.

Essas diretrizes sintetizam todo o esforço realizado pelo governo brasileiro em relação à gestão e implementação de programas e projetos de CSS. No entanto, conforme visto anteriormente, também foi fundamental nesse processo a consolidação de parcerias com órgãos internacionais, fundamentalmente as Nações Unidas e especialmente com o PNUD e com a Organização das Nações Unidas para Agricultura e Alimentação (FAO). Nesse sentido, Chediek (2017, p. 57) demonstra que o apoio da ONU à CSS brasileira pode ser analisado desde à criação da $\mathrm{ABC}$, em 1987. Especialmente em 2010, foi assinada uma parceria entre o governo brasileiro e 
o PNUD, que estendeu o apoio da agência para a cooperação técnica bilateral brasileira, ampliando a participação brasileira em plataformas multilaterais e aprimorando os centros de excelência. Segundo o mesmo autor:

(...) essa prolífica parceria, a partir de 2014, apresentava quatro tipos principais de apoio do PNUD à CSS brasileira: a) capacitação institucional; b) apoio programático e operacional à cooperação técnica bilateral e trilateral; c) pesquisa, coleta e sistematização de práticas e políticas brasileiras; e d) facilitação da partilha de conhecimentos e de "conexão" de parcerias (ibid.). Essas abordagens tinham como objetivo central: maximizar o grande potencial da cooperação técnica brasileira e suas bem-sucedidas boas práticas e políticas sociais.

Essa iniciativa gerou a criação de dois novos centros de excelência em pesquisa voltados para maximizar o potencial da CSS através das políticas sociais, sendo criado em 2011 o Centro de Excelência contra a Fome ${ }^{5}$ (que reproduz os êxitos do Programa Fome Zero em outros países em desenvolvimento) e, em 2013, o Centro Rio $+{ }^{6}$, ou Centro Mundial para o Desenvolvimento Sustentável (promovendo a CSS no âmbito da sustentabilidade) (CHEDIEK, 2017).

No entanto, Chediek (2017) e Fraundorfer (2013) chamam a atenção para outro centro de excelência - o primeiro deles - criado em 2004, o Centro Internacional de Políticas para o Crescimento Inclusivo (IPC-IG) ${ }^{7}$. Oficialmente gerado em 2002 como Centro Internacional de Pobreza (IPC), o IPC-IG estabeleceu conexões relevantes com vários atores da governança global, especialmente aqueles de combate à fome e à pobreza. Nesse sentido, "desde 2009 o Centro tem expandido esta rede através de seu envolvimento no Fórum Acadêmico do IBAS, do seminário de think tanks do BRIC e dos grupos de trabalho do G-20" (FRAUNDORFER, 2013, p. 104).

Em relação à parceria do governo brasileiro com a FAO, o diretor-geral da FAO, Graziano da Silva (2017) afirma que a cooperação é fundamental para o desenvolvimento da CSS, especialmente para a promoção da agricultura sustentável e da segurança alimentar, além do seu alinhamento com os ODS. O país ocupa atualmente a décima posição em relação a contribuição para a FAO e, para além do aspecto econômico, essa parceria teria como princípio utilizar e disseminar o vasto conhecimento brasileiro na área de combate à pobreza. Nesse sentido:

\footnotetext{
${ }_{5}^{5}$ Maiores informações em: < http://centrodeexcelencia.org.br/>

${ }^{6}$ Maiores informações em: < https://nacoesunidas.org/onu-no-brasil/centro-riopnud/>

7 Maiores informações em: < http://www.ipc-undp.org/pt-br/>
} 
Ao longo das duas últimas décadas, o Brasil tem apoiado mais de 30 projetos Sul-Sul no âmbito de diferentes memorandos e acordos assinados com a FAO. O Brasil é hoje como um dos parceiros mais importantes da FAO na Cooperação Sul-Sul. Isso é possível não apenas pelo exemplo dado a outros países oferecido pela sua própria história e experiência de desenvolvimento, mas porque as áreas sob mandato da FAO são também aquelas em que o Brasil desenvolveu fortes habilidades e conhecimentos. (GRAZIANO DA SILVA, 2017, p. 318).

Portanto, é notável o esforço do governo brasileiro para que a CSS despontasse como um mecanismo de propagar as políticas sociais realizadas no país (especialmente a partir do Programa Fome Zero), unindo a isso os interesses das Nações Unidas, maior protagonismo brasileiro internacional e uma pressão ascendente por uma cadeira permanente no Conselho de Segurança da ONU. Os resultados são claros ao demonstrar os centros de excelência gerados, os programas e projetos voltados para a CSS, bem como a elevação dos recursos disponíveis, com destaque para o período entre 2005 e 2010.

Entretanto, também é notável que há uma perda de fôlego no crescimento dos recursos disponíveis a partir de 2011 e, especialmente após a crise política e econômica instaurada no Brasil atualmente (com destaque para o período pós impeachment) é necessário refletir acerca dos seus possíveis efeitos sobre a CSS e sua garantia (ou não) de continuidade, tema a ser discutido na próxima seção.

\section{4. (Possíveis) Efeitos da Atual Crise sobre a CID e a CSS}

Desde 2014, com a reeleição da ex-presidenta Dilma Rousseff, o Brasil vem perpassando por uma crise política e econômica significativa que, por diversas razões, culminou no impeachment da ex-presidenta em agosto de 2016. Antes mesmo do encerramento do processo, em outubro de 2015, foi lançado o Plano "Uma Ponte para o Futuro", elaborado pelo até então Partido do Movimento Democrático Brasileiro (PMDB) - do qual era membro o vice-presidente da República, Michel Temer - e pela Fundação Ulysses Guimarães.

No plano, conforme analisado na primeira seção do artigo, a preocupação fundamental era reestabelecer o crescimento econômico e o controle do endividamento público através de um conjunto de reformas, dentre elas: o ajuste fiscal e as reformas trabalhista e previdenciária. Logo após o impeachment, Michel Temer foi empossado como presidente interino e esse plano de governo passou a liderar os rumos país. É fundamental destacar a mudança de postura do governo interno frente aos governos anteriores, através do absoluto enfoque e esforços para 
a realização e votação da Emenda Constitucional 55, que estabeleceu um teto para o crescimento das despesas vinculadas à inflação para os próximos 20 anos (Ulhôa e Almeida Filho, 2018).

A EC 55, conforme apontam Silva e Almeida Filho (2018), já apresenta efeitos negativos em áreas prioritárias da política social, como por exemplo: na saúde e educação, com diminuição das despesas em 3,1\% entre 2016 e 2017, congelando os gastos de $\mathrm{R} \$ 191,2$ bilhões para $\mathrm{R} \$ 191,3$ bilhões. Na assistência social os programas funcionam normalmente, mas os reajustes já estão sendo afetados, uma vez que em 2018 espera-se que o Bolsa Família sofra um reajuste de cerca de 3\%, enquanto que em 2017 o mesmo reajuste foi de $16,39 \%$.

É evidente que se política social está sofrendo com os cortes no orçamento federal, consequentemente os programas e projetos não obterão o destaque que obtinham anteriormente e, também por consequência, as iniciativas relativas à CSS serão afetadas, visto que em sua grande maioria elas estão interligadas com a disseminação de boas práticas brasileiras na política social.

Dessa forma, foi demonstrado como os governos petistas enfocaram no destaque regional e na CSS como uma das estratégias fundamentais. Nesse novo cenário, desde o plano de governo a CSS não é mencionada e o único ponto onde alguma questão internacional emerge é em relação ao comércio internacional, especialmente na maior abertura comercial e na busca por acordos regionais voltados também ao comércio, com destaque para as negociações com os Estados Unidos, a União Europeia e a Ásia, que poderão ser feitos com ou sem a participação do Mercosul, evidenciando que o novo governo tem como meta privilegiar as antigas relações de cooperação Norte-Sul, reforçando o caráter imperialista do sistema internacional.

O ministro das relações exteriores, Aloysio Nunes Ferreira, escreveu a apresentação do livro "3o Anos da ABC: Visões da Cooperação Técnica Internacional Brasileira" lançado em 2017 e, na oportunidade, afirmou que o atual governo "está firmemente comprometido em reforçar a cooperação técnica internacional como instrumento de ação da diplomacia brasileira" (FERREIRA, 2017, p. 9). Além disso, o ministro ainda afirma que a diversificação brasileira em relação à cooperação permitiu fortificar as relações internacionais (regionais ou não), atraindo agências governamentais e organismos internacionais para a troca de experiências e parcerias. É possível identificar que em poucas oportunidades o Ministro chama a atenção para a CSS, enquanto que ao final demonstra a importância da interação com países desenvolvidos, organizações internacionais e regionais na ação brasileira internacional, ou seja, discretamente proporciona maior destaque para a cooperação no eixo Norte-Sul.

Entretanto, em termos práticos, uma das primeiras medidas do atual governo em relação à cooperação internacional foi, em setembro de 2016, extinguir a CG 
Fome, órgão que, conforme visto anteriormente, tinha como função coordenar as ações brasileiras de combate à fome em outros países. Segundo a reportagem ${ }^{8}$, foi realizada uma reforma administrativa que redistribuiu as competências dentro do Ministério das Relações Exteriores, através da diminuição da sua estrutura e através da devolução de mais de 40 cargos comissionados.

Além disso, o Itamaraty ressaltou que essa mudança fez com que as atividades realizadas anteriormente pela CG Fome fossem distribuídas em outros setores, mantendo a sua continuidade através da $A B C$ e da Divisão de Temas Sociais (DTS). Entretanto, na mesma reportagem, a ex-ministra do Desenvolvimento Social Tereza Campello, afirma que a extinção do departamento pode ser um sinal de que o atual governo não pretende continuar a cooperar nessa área, o que colocaria o país em uma situação problemática uma vez que a agenda de combate à fome brasileira tem significativo reconhecimento das Nações Unidas.

Enquanto no plano de governo e na fala do Ministro das Relações Exteriores haviam indícios de que a CSS não obteria a mesma relevância que obteve nos governos anteriores, a extinção da CGFome foi um primeiro passo efetivo nesse sentido. Em conjunto, o congelamento de gastos na área social já demonstra efeitos reais no aumento da pobreza e da desigualdade no Brasil, o que poderá diminuir o papel brasileiro como exemplo internacional no combate à pobreza.

Portanto, é nítido que tanto a política social, como por consequência a CSS vêm sofrendo modificações após a chegada do governo interino, o que colocam em dúvida a sua capacidade de sobrevivência a longo prazo. Dessa forma, é necessário destacar mais uma vez o caráter governamental dessas políticas que, apesar de tratarem de um tema tão relevante como o combate à miséria e à desigualdade, continuam a mercê das vontades políticas em voga. Também é preciso salientar que, em nenhum dos governos analisados, a interação brasileira (especialmente a comercial) com os países do eixo Norte foi abalada, ou seja, a base do sistema imperialista internacional foi preservada e, de acordo com o plano de governo atual, pretende-se estreitar ainda mais esses laços comerciais verticais (com ou sem a presença do Mercosul).

\footnotetext{
${ }^{8}$ Acesso à reportagem em: < https://www1.folha.uol.com.br/mundo/2016/o9/1813599-itamaratyextingue-departamento-de-combate-a-fome.shtml>
} 


\section{Considerações Finais}

Ao observar historicamente o sistema internacional, o Brasil sempre apresentou um posicionamento diplomático à frente da maioria dos conflitos, retirando o foco da preocupação do país com a segurança nacional e colocando-o nas relações comerciais. Essa característica da imersão internacional brasileira também se repetiu na maioria dos demais países latino-americanos, uma vez que a grande maioria deles realizou um alinhamento pragmático aos Estados Unidos que, até os dias atuais, é um dos grandes responsáveis pela manutenção de um sistema internacional imperialista, centrado nas relações comerciais verticais, aquelas realizadas entre o eixo dos países do Norte com o Sul.

Após a Segunda Guerra Mundial, a partir da necessidade de reconstruir as nações atingidas se iniciou um processo de maior multilateralismo nas relações internacionais, com destaque para a atuação das Nações Unidas no processo de unir diversos países em torno das necessidades relativas ao desenvolvimento mundial, a CID. No Brasil, foi somente após a Era Vargas e ainda mais intensificado com a Guerra Fria, que a cooperação realizada com outros países periféricos começou a se intensificar.

No entanto, os anos 2000 foram os anos em que a cooperação entre os países do Sul cresceu exponencialmente, colocando em destaque a CSS. Isso porque, especialmente nos governos do ex-presidente Lula, o país viveu um período de crescimento econômico expansivo, diversas estratégias de combate à pobreza e à desigualdade foram desenhadas e implementadas com sucesso e, ao mesmo tempo, o governo tinha como desejo alcançar maior expressividade no Conselho de Segurança da ONU. Em paralelo, as Nações Unidas também lançaram nos anos 2000 os ODM, que atualmente compõe os ODS e a Agenda 2030, com foco primordial no combate à pobreza em todas as suas dimensões.

A partir de objetivos em comum, a parceria entre as agências da ONU com o Brasil se elevou consideravelmente, com destaque para a inauguração de três centros de excelência em pesquisa sobre desenvolvimento, CSS e a implementação de programas para garantir a segurança alimentar (esse último em parceria com a FAO). No entanto, vale ressaltar que em nenhum momento o país deixou de realizar sua cooperação vertical com os países do Norte (em especial no que diz respeito às negociações comerciais), ou seja, a manutenção do sistema internacional baseado no imperialismo continuou como uma constante.

As agendas da CID e da CSS brasileira foram muito além das questões relativas às doações e às ajudas humanitárias; discutiam políticas públicas e formas de inserção nos outros países através da cooperação e geração de parcerias. O principal objetivo era difundir os conhecimentos adquiridos com o Fome Zero (e as iniciativas oriundas dele) para apoiar os gestores internacionais que obtinham 
o interesse de realizar programas semelhantes em seus países, com destaque para o eixo Sul.

Os estudos que avaliam o influxo monetário que o país realizou entre $2005 \mathrm{e}$ 2013 na CID demonstram que esses valores sextuplicaram entre 2005 e 2009 e, em alguns anos, ultrapassaram R 1 bilhão. No entanto, é notável uma diminuição no crescimento contínuo dos valores, especialmente entre 2011 e 2013. Outro destaque necessário está na incapacidade de quantificar a troca de conhecimentos e experiências entre esses países, fator preponderante na CSS brasileira. Dessa forma, os resultados evidenciam uma confirmação da hipótese formulada inicialmente, uma vez que foi verificado conteúdo fortemente inovador nos governos Lula em relação à cooperação internacional que, se não foi capaz de promover o Brasil para uma cadeira permanente no Conselho de Segurança da ONU, obteve sucesso em elevar consideravelmente essas parcerias, principalmente via criação de inúmeros projetos de cooperação trilateral.

Entretanto, a mudança de governo após o processo de impeachment trouxe consigo sinais de que o enfoque dado à CDI e à CSS poderá não ser o mesmo realizado no passado. Indícios dessa reversão já são encontrados desde o plano de governo, que não cita essas modalidades de cooperação e, ao contrário, coloca em destaque as negociações comerciais com os países do Norte. Em termos práticos, uma das primeiras ações do novo governo foi extinguir a CGFome, coordenação criada para ajudar a gerir a CSS e a troca de experiências no combate à pobreza dentro do Ministério das Relações Exteriores. Segundo informações do Itamaraty as funções desenvolvidas pela CGFome não serão extintas, mas sim delegadas a outros setores. Ainda assim, há uma probabilidade alta de que a quebra dessa institucionalidade gere desconforto na continuidade das ações.

Portanto, é indiscutível a importância que a CDI e a CSS obtiveram nos últimos anos no Brasil e como esse esforço se materializou nos centros de excelência em pesquisa e em iniciativas concretas de combate à fome e a desigualdade. Infelizmente, a partir do novo governo com o cenário de crise e ajuste fiscal, os efeitos sobre a cooperação internacional para o desenvolvimento já se colocam como negativos, com perspectiva de piora para os próximos anos. 


\section{Referências Bibliográficas}

AGÊNCIA BRASILEIRA DE COOPERAÇÃO (ABC). Manual de gestão da cooperação técnica Sul-Sul. Edição da $A B C$, Brasília, 2013.

ALMINO, J. Introdução. In: ALMINO, J.; LIMA, S. E. M. (Orgs). 30 Anos da ABC: Visões da cooperação técnica internacional brasileira. Fundação Alexandre Gusmão, Brasília, 2017.

AMORIM, C. A diplomacia multilateral do Brasil: Um tributo a Rui Barbosa. In: Palestra do Ministro das Relações Exteriores na II Conferência Nacional de Política Externa e Política Internacional - O Brasil e o Mundo que vem aí. Fundação Alexandre de Gusmão, Rio de Janeiro, Palácio Itamaraty, 2007.

BURGES, S. Desenvolvendo a partir do Sul: Cooperação Sul-Sul no jogo de Desenvolvimento Global. Revista Brasileira de Estratégia e Relações Internacionais, v.1, n.2, 2012.

CARVALHO, L. Valsa Brasileira: do Boom ao Caos Econômico. São Paulo: Todavia, 2018.

CHEDIEK, J. O papel do Brasil na cooperação sul-sul: Um estudo analítico e histórico. In: ALMINO, J.; LIMA, S. E. M. (Orgs). 30 Anos da ABC: Visões da cooperação técnica internacional brasileira. Fundação Alexandre Gusmão, Brasília, 2017.

FERREIRA, A. N. Apresentação. In: ALMINO, J.; LIMA, S. E. M. (Orgs). 30 Anos da ABC: Visões da cooperação técnica internacional brasileira. Fundação Alexandre Gusmão, Brasília, 2017.

FRAUNDORFER, M. Fome Zero para o Mundo - A Difusão Global Brasileira do Programa Fome Zero. Revista Brasileira de Estratégia e Relações Internacionais, v.2, n. 4, e-ISSN 2238-6912, 2012.

GRAZIANO DA SILVA, J. O Brasil e a FAO: Parceria por um mundo sem fome. In: ALMINO, J.; LIMA, S. E. M. (Orgs). 30 Anos da ABC: Visões da cooperação técnica internacional brasileira. Fundação Alexandre Gusmão, Brasília, 2017.

GUIMARÃES, S. P. O imperialismo, o sistema internacional e o Brasil: Reflexões sobre a política internacional. Editora Fundação Perseu Abramo. São Paulo, 2013. 
HIRST, M. Aspectos Conceituais e Práticos da Atuação do Brasil em Cooperação SulSul: Os Casos de Haiti, Bolívia e Guiné Bissau. In: Texto para Discussão no 1687. Instituto de Pesquisa Econômica Aplicada, Rio de janeiro, janeiro de 2012.

INSTITUTO DE PESQUISA ECONÔMICA APLICADA (IPEA); AGÊNCIA BRASILEIRA DE COOPERAÇÃO (ABC). Cooperação brasileira para o desenvolvimento internacional: 2005-2009. Brasília, 2010.

INSTITUTO DE PESQUISA ECONÔMICA APLICADA (IPEA); AGÊNCIA BRASILEIRA DE COOPERAÇÃO $(\mathrm{ABC})$. Cooperação brasileira para o desenvolvimento internacional: 2011-2013. Brasília, 2016.

LIMA, S. E. M.. A gênese e evolução da ABC. In: ALMINO, J.; LIMA, S. E. M. (Orgs). 30 Anos da ABC: Visões da cooperação técnica internacional brasileira. Fundação Alexandre Gusmão, Brasília, 2017.

MARQUES, R. M.; MENDES, Á. Servindo a dois senhores: As políticas sociais no governo Lula, Revista Katál. Florianópolis, v. 10, № 1, 2007.

MELLO, F. C. O Brasil e o Multilateralismo Contemporâneo. Texto para Discussão, no1628. Instituto de Pesquisa Econômica Aplicada (IPEA), Brasília, 2011.

MILANI, C. R. Aprendendo com a história: Críticas à experiência da Cooperação Norte-Sul e atuais desafios à Cooperação Sul-Sul. Caderno CRH, vol. 25, núm. 65 . Universidade Federal da Bahia, Salvador, 2012.

OSÓRIO, R. Desigualdade e Pobreza. In: CALIXTRE, A.; VAZ, F. PNAD 2014 Breves Análises. Nota Técnica do Instituto de Pesquisa Econômica Aplicada (IPEA), Brasília, no 22, dezembro de 2015.

PECEQUILO, C. S. O Brasil e os eixos periféricos: agenda e identidade nas relações internacionais. Cadernos de Estudos Culturais, vol. 4, 2012.

PECEQUILO, C. S. A Política Externa do Brasil no Século XXI: Os Eixos Combinados de Cooperação Horizontal e Vertical. Revista Brasileira de Política Internacional, n. 51, v.2, 2008.

REPÚBLICA FEDERATIVA DO BRASIL. Mensagem ao Congresso Nacional: Presidente Luís Inácio Lula da Silva. IPEA/IPLAN. Documentação Oficial, 2003.

SILVA, P. A. O. Social Policy in Brazil (2004-2014): An overview, Policy in Focus. Working Paper no 155, Brasília, 2017. 
SILVA, P. A. O.; ALMEIDA FILHO, N. O Regime Fiscal e a Política Social no Brasil: Análise recente e desafios. Em processo de submissão, 2018.

SOARES DE LIMA, M. R. A política externa brasileira e os desafios da cooperação Sul-Sul. Revista Brasileira de Política Internacional, vol. 48, núm. 1. Brasília, 2005 .

SOUZA, P. H. G. F. Poverty, Inequality and Social Policies in Brazil, 1995-2009. Brasília, International Policy Center for Inclusive Growth. Working Paper no 87, February 2012.

TESOURO NACIONAL. Gasto Social do Governo Central, 2002 a 2015. Brasília, 2016.

ULHÔA, W. M. M.; ALMEIDA FILHO, N. Estado e Políticas Públicas sob o "Novo Regime Fiscal". Anais do XXIII Encontro Nacional de Economia Política, Universidade Federal Fluminense. Niterói: 12 a 15 de junho de 2018. 